\title{
Modeling day-to-day ionospheric variability on Mars
}

\author{
Carlos R. Martinis, Jody K. Wilson, and Michael J. Mendillo \\ Center for Space Physics, Boston University, Boston, Massachusetts, USA \\ Received 4 April 2003; revised 8 July 2003; accepted 25 July 2003; published 29 October 2003.
}

[1] We use a simple photochemical model of Mars' ionosphere to investigate the changes in calculated electron density profiles, $\mathrm{Ne}(\mathrm{h})$, under the assumption that the only variable parameter is the solar irradiance. The period under study is 9-27 March 1999, corresponding to a series of $\mathrm{Ne}(\mathrm{h})$ observations made by the Mars Global Surveyor (MGS) Radio Science (RS) experiment. The SOLAR 2000 model is used to obtain the solar irradiances during this period. Secondary ionization is included and is expressed as a simple function of photoionization. The model uses several neutral gas species, five of which $\left(\mathrm{CO}_{2}, \mathrm{~N}_{2}, \mathrm{CO}, \mathrm{NO}, \mathrm{O}\right)$ experience photoionization. Subsequent ion-neutral chemistry leads to an ionosphere with five ions species. Using average solar conditions for March 1999, good agreement was obtained between the model's mean electron density profile and the mean electron densities from the MGS observations. Modeling day-to-day changes using daily solar irradiance values resulted in $\sim 6 \%$ and $19 \%$ variabilities for the major and secondary layer peak densities, respectively, in good agreement with the observed values of 5 and $10 \%$. The variable photon flux from the Sun is thus the primary driver of day-to-day changes in the peak electron densities on Mars. INDEX TERMS: 2459 Ionosphere: Planetary ionospheres (5435, 5729, 6026, 6027, 6028); 2447 Ionosphere: Modeling and forecasting; 6225 Planetology: Solar System Objects: Mars; 1650 Global Change: Solar variability; 2479 Ionosphere: Solar radiation and cosmic ray effects; KEYWORDS: ionosphere, Mars, variability, modeling, solar irradiance, Mars Global Surveyor

Citation: Martinis, C. R., J. K. Wilson, and M. J. Mendillo, Modeling day-to-day ionospheric variability on Mars, J. Geophys. Res., 108(A10), 1383, doi:10.1029/2003JA009973, 2003.

\section{Introduction}

[2] The ionosphere of Mars offers a rich blend of space plasma and aeronomic processes over a small range of heights. With no global magnetic field to hold off the solar wind, the topside ionosphere can have its "ionopause" between $\sim 300$ and $\sim 500 \mathrm{~km}$, depending on the strength of the solar wind [Vignes et al., 2000; Crider et al., 2001; Vignes et al., 2002]. The neutral atmosphere at these heights is almost entirely atomic oxygen at low number densities $\left(10^{7}-10^{6}\right.$ atoms $\left./ \mathrm{cm}^{3}\right)$ that comprise an escaping corona [Fox, 1997]. The ionosphere at these heights is not produced locally by the photoionization of $\mathrm{O}$ but rather by upward diffusion of $\mathrm{O}_{2}{ }^{+}$ions produced at lower altitudes [Nagy and Cravens, 2002]. Near $200 \mathrm{~km}$, the atmospheric scale height and the mean free path for neutrals are approximately the same, and this is the base of the exosphere. Several scale heights below, at $\sim 125-135 \mathrm{~km}$, there is an ionospheric peak, followed by a secondary layer at $\sim 90-110 \mathrm{~km}$. Below $\sim 80 \mathrm{~km}$, there is negligible ionization.

[3] Compared with the terrestrial case, the above description comes from a remarkably sparse database. Models of early datasets have, nevertheless, provided a firm basis for our physical understanding of the planet's upper atmosphere.

Copyright 2003 by the American Geophysical Union. 0148-0227/03/2003JA009973\$09.00
The region of peak density near $135 \mathrm{~km}$ occurs in a neutral background density of $\sim 10^{11}$ molecules $/ \mathrm{cm}^{3}$, conditions familiar to modelers of the Earth's E-region. Under such conditions, the time constants for photochemical processes (production and loss) are shorter than for plasma diffusion, and thus ionospheric structure in latitude and longitude are well modeled by solar zenith angle and local time using the relatively simple "Chapman equations" for photochemical equilibrium (i.e., no plasma transport) for a single-species atmosphere, as described by Rishbeth and Garriott [1969], Banks and Kockarts [1973], and Schunk and Nagy [2000]. In practice, more sophisticated codes are used, ones with multiple species for photoproduction, subsequent ion-neutral transformations, and multiple loss paths, to describe the general photochemical behavior of the Martian ionosphere. Fox et al. [1995] have given a comprehensive description of solar cycle effects using a one-dimensional (1-D) model, while the general circulation model (GCM) approach has been used for seasonal and solar cycle conditions by Bougher and Roble [1991], Bougher et al. [1999, 2000, 2002], and Winchester and Rees [1995].

[4] In this paper, we use the photochemical framework in a first study of day-to-day ionospheric variability patterns on Mars, modeling observations from the Mars Global Surveyor (MGS) satellite. Figure 1 shows 17 daily $\mathrm{Ne}(\mathrm{h})$ profiles obtained at Mars in March 1999 [Mendillo et al., 2003]. Our goal is to see if the day-to-day variability in solar irradiance on those days can account 

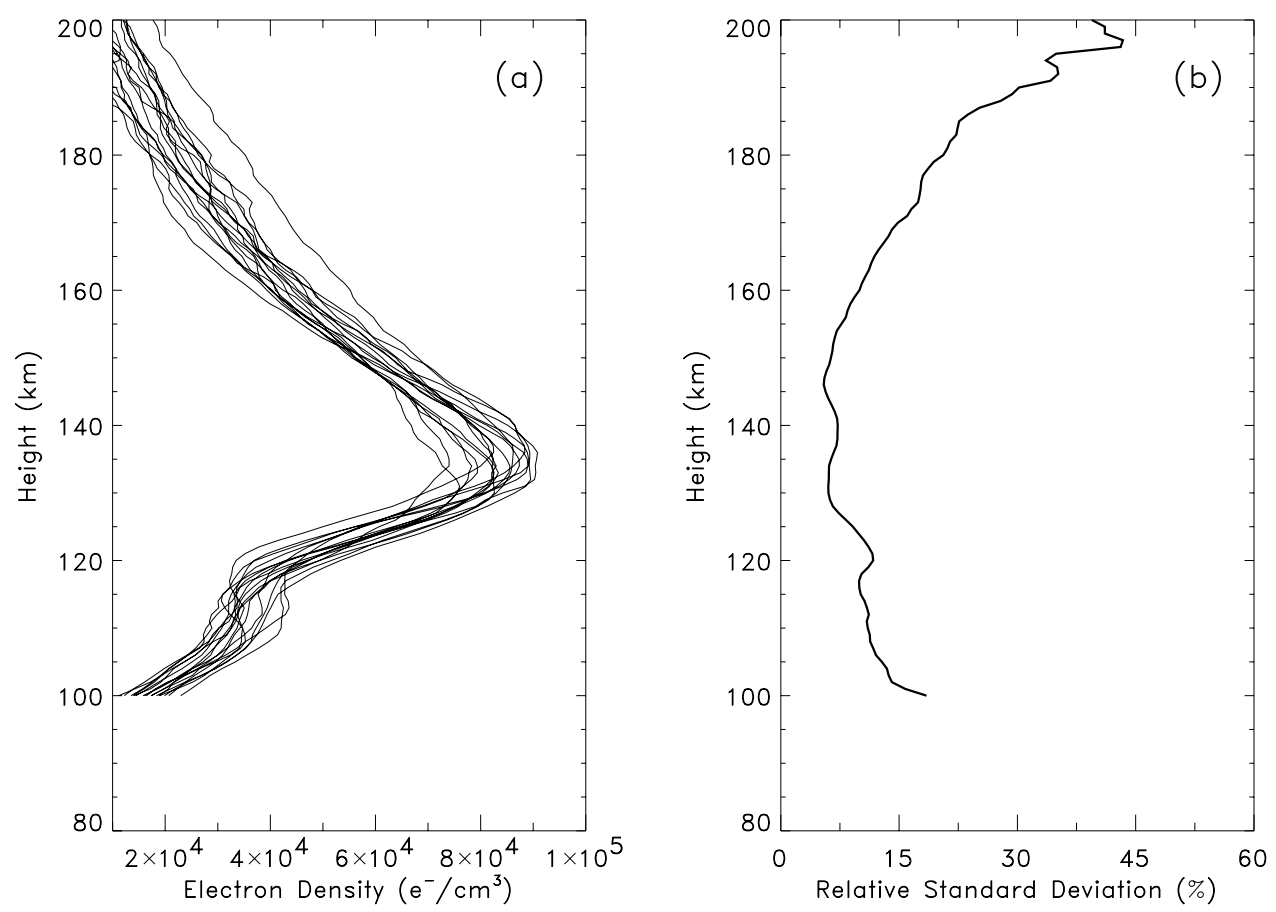

Figure 1. Mars electron density profiles obtained by the MGS radio science experiment during March 1999. (a) Seventeen daily mean profiles and (b) their variability (defined as the standard deviation about the sample mean). All observations refer to high latitudes $\left(\sim 71^{\circ} \mathrm{N}\right)$ under sunlit conditions at $\sim 0400$ local time. Taken from Mendillo et al., [2003].

for the $\sim 5 \%$ variability at the main peak and the $\sim 10 \%$ variability in the secondary layer.

\section{Modeling}

\subsection{Approach to Modeling a Specific Mechanism}

[5] To study the effects of one parameter in a multifaceted system, it is clearly best to hold all others constant. Thus while changes in solar irradiance will cause some changes in the altitude profiles of Mars' upper atmospheric constituents, as well as modify its thermospheric temperature, we will fix those parameters in order to isolate the effects of ionization from a changing solar photon source. As reviewed recently by Bougher et al. [2002], there are diurnal, seasonal, and solar cycle effects in the Martian thermosphere, and thus changes in solar input conditions obviously matter. Compared with the terrestrial case, however, they are rather modest in magnitude and particularly so near $135 \mathrm{~km}$ and below. Adopting a fixed thermosphere for our study thus has its limitations, but it should illuminate clearly how day-to-day solar irradiance changes affect ionospheric production on Mars and consequently the variability of its electron density profiles.

\subsection{Model Description}

[6] To model Mars' basic ionospheric structure in the photochemical framework, we solve the standard ion continuity equation for production and loss,

$$
\frac{\partial \mathrm{N}}{\partial \mathrm{t}}=\mathrm{P}-\mathrm{L},
$$

where $\mathrm{N}$ represents ion density, $\mathrm{P}$ its production rate from a parent neutral, and $\mathrm{L}$ represents its loss processes.
Equation (1) is valid when chemical time scales are small compared to transport time constants.

[7] The loss rate of a given ion is proportional to its original abundance, $L=R N$, with $R$ (units $s^{-1}$ ) representing the loss rate due to ion-molecule reactions $(\mathrm{R}=\beta)$ and/or dissociative recombination $\left(\mathrm{R}=\alpha \mathrm{N}_{\mathrm{e}}\right)$, where $\alpha$ and $\beta$ are the usual Chapman parameters for loss. Equation (1) then becomes a first-order linear differential equation. Under the assumption that $\mathrm{P}$ and $\mathrm{R}$ are constant, which is valid over a sufficiently small time range, the solution of equation (1) can be expressed as

$$
\mathrm{N}=\mathrm{N}_{0} \mathrm{e}^{-\mathrm{Rt}}+\frac{\mathrm{P}}{\mathrm{R}}\left(1-\mathrm{e}^{\mathrm{Rt}}\right)
$$

or, replacing t with $\Delta \mathrm{t}$,

$$
\Delta \mathrm{N}=\left(1-\mathrm{e}^{\mathrm{R} \Delta \mathrm{t}}\right)\left(\frac{\mathrm{P}}{\mathrm{R}}-\mathrm{N}_{0}\right)
$$

where $\Delta \mathrm{N}$ is the change in $\mathrm{N}$ over the time interval $\Delta \mathrm{t}$. Our method is more accurate and more stable than the basic approach $(\Delta \mathrm{N}=[\mathrm{P}-\mathrm{R}] \Delta \mathrm{t})$, which assumes a constant rate of change over each interval. Sometimes, this produces computational instabilities where $\Delta \mathrm{N}$ may "overshoot" the natural equilibrium of $\mathrm{N}=\mathrm{P} / \mathrm{R}$. Equation (2), on the other hand, includes the realistic asymptotic approach to equilibrium in each time step, allowing for larger and more accurate time steps without computational instability.

[8] A set of five main neutral species is used $\left(\mathrm{CO}_{2}, \mathrm{~N}_{2}, \mathrm{O}\right.$, $\mathrm{CO}$, and $\mathrm{Ar}$ ), with altitude profiles corresponding approximately to the MGS observations in March 1999, a period of 
Table 1. Reaction Rates for the Neutral and Plasma Species Used in the Model [Schunk and Nagy, 2000]

\begin{tabular}{lc}
\hline \multicolumn{1}{c}{ Reaction } & Rate Constant, $\mathrm{cm}^{3} / \mathrm{s}$ \\
\hline $\mathrm{CO}_{2}^{+}+\mathrm{O} \rightarrow \mathrm{O}^{+}+\mathrm{CO}_{2}$ & $\mathrm{k}_{1} 9.6 \times 10^{-11}$ \\
$\mathrm{CO}_{2}^{+}+\mathrm{O} \rightarrow \mathrm{O}_{2}^{+}+\mathrm{CO}$ & $\mathrm{k}_{2} 1.6 \times 10^{-10}$ \\
$\mathrm{CO}_{2}^{+}+\mathrm{NO} \rightarrow \mathrm{NO}^{+}+\mathrm{CO}_{2}$ & $\mathrm{k}_{3} 1.2 \times 10^{-10}$ \\
$\mathrm{~N}_{2}^{+}+\mathrm{CO}_{2} \rightarrow \mathrm{CO}_{2}^{+}+\mathrm{N}_{2}$ & $\mathrm{k}_{4} 8.0 \times 10^{-10}$ \\
$\mathrm{~N}_{2}^{+}+\mathrm{O} \rightarrow \mathrm{O}^{+}+\mathrm{N}_{2}$ & $\mathrm{k}_{5} 9.8 \times 10^{-12}$ \\
$\mathrm{~N}_{2}^{+}+\mathrm{O} \rightarrow \mathrm{NO}^{+}+\mathrm{N}$ & $\mathrm{k}_{6} 1.3 \times 10^{-10}$ \\
$\mathrm{~N}_{2}^{+}+\mathrm{NO} \rightarrow \mathrm{NO}^{+}+\mathrm{N}_{2}$ & $\mathrm{k}_{7} 4.1 \times 10^{-10}$ \\
$\mathrm{O}^{+}+\mathrm{NO} \rightarrow \mathrm{NO}^{+}+\mathrm{O}$ & $\mathrm{k}_{8} 8.0 \times 10^{-13}$ \\
$\mathrm{O}^{+}+\mathrm{N}_{2} \rightarrow \mathrm{NO}^{+}+\mathrm{N}$ & $\mathrm{k}_{9} 1.2 \times 10^{-12}$ \\
$\mathrm{O}^{+}+\mathrm{CO} \rightarrow \mathrm{O}_{2}^{+}+\mathrm{CO}$ & $\mathrm{k}_{10} 1.1 \times 10^{-9}$ \\
$\mathrm{O}_{2}^{+}+\mathrm{NO}^{+} \rightarrow \mathrm{NO}^{+}+\mathrm{O}_{2}$ & $\mathrm{k}_{11} 4.6 \times 10^{-10}$ \\
$\mathrm{CO}_{2}^{+}+\mathrm{e}^{-} \rightarrow \mathrm{CO}+\mathrm{O}$ & $\alpha_{1} 3.1 \times 10^{-7} \times\left(300 / \mathrm{T}_{\mathrm{e}}\right)^{0.5}$ \\
$\mathrm{~N}_{2}^{+}+\mathrm{e}^{-} \rightarrow \mathrm{N}+\mathrm{N}$ & $\alpha_{2} 2.2 \times 10^{-7} \times\left(300 / \mathrm{T}_{\mathrm{e}}\right)^{0.39}$ \\
$\mathrm{O}_{2}^{+}+\mathrm{e}^{-} \rightarrow \mathrm{O}+\mathrm{O}$ & $\alpha_{3} 1.95 \times 10^{-7} \times\left(300 / \mathrm{T}_{\mathrm{e}} \mathrm{e}^{0.7}\right.$ for $\mathrm{T}_{\mathrm{e}}<1200$ \\
$\mathrm{NO}^{+}+\mathrm{e}^{-} \rightarrow \mathrm{N}+\mathrm{O}$ & $\alpha_{4} 4.0 \times 10^{-7} \times\left(300 / \mathrm{T}_{\mathrm{e}}\right)^{0.5}$ \\
\hline
\end{tabular}

moderate solar activity (average F10.7 130). We have taken the neutral atmosphere in the work of Fox et al. [1995] for solar maximum conditions as the most appropriate "fixed atmosphere" available in the published literature for our computational experiments. Minor species (NO, He, $\mathrm{H}_{2}, \mathrm{H}$ ) were obtained from A. Nagy (private communication, 2002). The calculations are conducted using spherical geometry for the planet, with solutions to the continuity equation for production and loss using five ion species. The major ions are $\mathrm{O}_{2}^{+}$and $\mathrm{CO}_{2}^{+}$, but the electron density is formed by summing over all five ions $\left(\mathrm{O}_{2}^{+}, \mathrm{CO}_{2}^{+}, \mathrm{O}^{+}, \mathrm{N}_{2}^{+}\right.$, and $\mathrm{NO}^{+}$) from 80 to $400 \mathrm{~km}$. The use of such high altitudes (heights probably above the ionopause) is needed for the correct calculations of solar photon attenuation down to the photochemical regime. However, we portray the resultant $\mathrm{Ne}(\mathrm{h})$ profiles from the model only to a height of $200 \mathrm{~km}$, and our interest is centered primarily on heights below $150 \mathrm{~km}$ where photochemistry dominates.

[9] Table 1 summarizes the 15 chemical reactions used and their rate coefficients. The electron temperature is needed for some of the reaction rates, and we assume it is equal to the neutral temperature, an approximation valid particularly at lower altitudes. Ionization due to photoelectrons (i.e., secondary ionization) has not been calculated directly. Instead, we parameterize it as a fraction of the primary photoionization. For altitudes higher than $120 \mathrm{~km}$, a ratio of secondary ionization to photoionization of 0.3 is used; at lower altitudes the ratio is 10 . This approximation is consistent with the approach presented by Fox et al. [1995].

[10] For solar production we use the SOLAR 2000 model, version 1.24 [Tobiska et al., 2000; Tobiska, 2003], an empirical model of the full solar spectrum that draws upon ground-based and satellite measurements available for each day. The irradiances are presented in 39 wavelength bins, from $1.8 \mathrm{~nm}$ to $105 \mathrm{~nm}$. The top of our neutral atmosphere is at $400 \mathrm{~km}$. Neutral species will absorb solar radiation and the remaining flux will ionize some of them. Absorption and ionization cross sections from 5 to $100 \mathrm{~nm}$ are taken from Schunk and Nagy [2000]. For the lower two bins (from 1.8 to $5 \mathrm{~nm}$ ) the ionization cross sections are calculated from the analytic fits of Verner et al. [1996]. Finally, in March 1999, Mars was nearly in opposition and so the Earth-appropriate (1 AU) output from SOLAR 2000 was adjusted only by the distance correction to Mars' orbit at $1.52 \mathrm{AU}$.

[11] As a demonstration of model output, we show in Figure 2 the wavelength-dependent ionization profiles for $\mathrm{CO}_{2}$ under conditions of an overhead Sun. Because of the rapid conversion of $\mathrm{CO}_{2}^{+}$to $\mathrm{O}_{2}^{+}$(see rate $\mathrm{k}_{2}$ in Table 1 ), these are essentially the production profiles of Mars' major ion
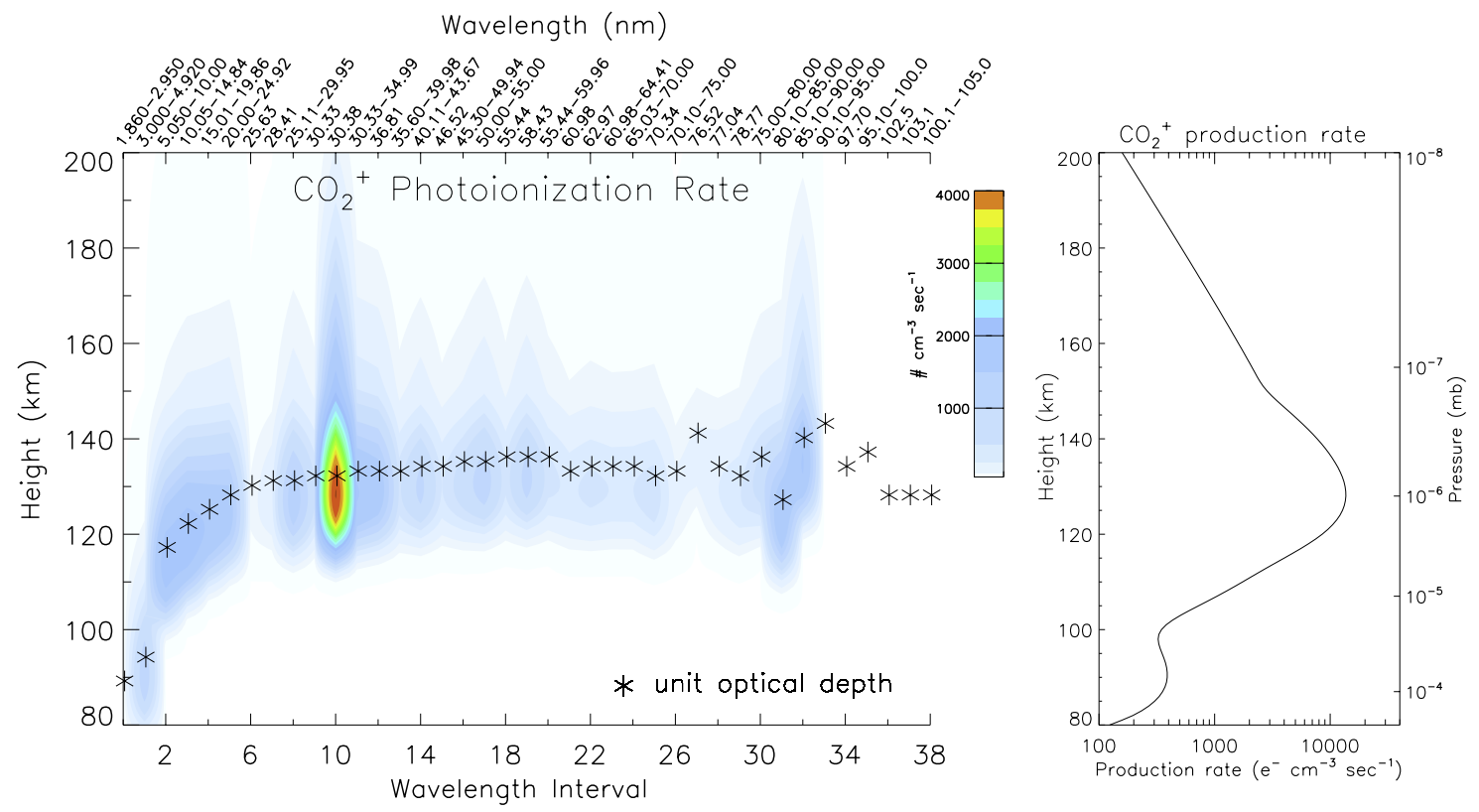

Figure 2. Model calculations for the photo-production of $\mathrm{CO}_{2}^{+}$by an overhead Sun, using solar maximum conditions $(\mathrm{F} 10.7=200)$. The contribution of each wavelength bin from the SOLAR 2000 model is shown. The right panel gives the wavelength-integrated production rate versus height and pressure levels in mbar. 

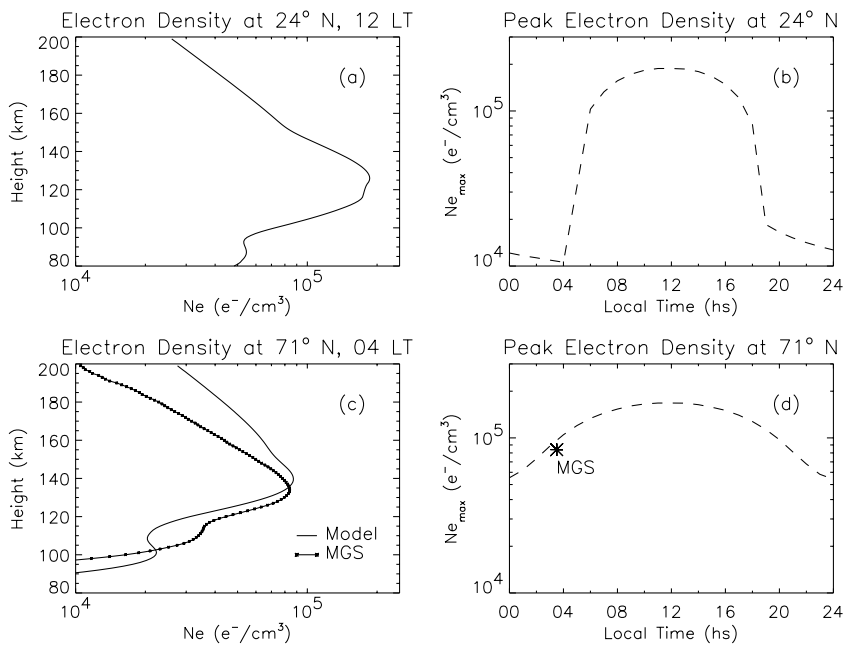

Figure 3. Photochemical model results for Mars' ionosphere in March 1999. (a) Electron density profile for the subsolar point; (b) diurnal variation of the peak electron density at the sub-solar point; (c) average electron density profile representative of MGS observations: lat $=71^{\circ} \mathrm{N}$ and $\mathrm{LT}=0400 ;$ (d) diurnal variation of average peak electron density at $71^{\circ} \mathrm{N}$. The average profile from the MGS observations in Figure 1 is also shown in Figure $3 c$ and its peak density is shown in Figure $3 d$.

$\left(\mathrm{O}_{2}^{+}\right)$. Note that the peak production is slightly below the height of unit optical depth and that the wavelength-integrated production rate has two peaks in altitude. There is no production of $\mathrm{CO}_{2}{ }^{+}$from the last six wavelength bins because the ionization potential for $\mathrm{CO}_{2}(13.77 \mathrm{eV})$ requires photons with wavelengths $<90.04 \mathrm{~nm}$. The main peak is produced by photons with $\lambda \cong 30-90 \mathrm{~nm}$ (dominated by the He line at $30.4 \mathrm{~nm}$, as observed previously for Venus [Keating and Bougher, 1992]), while the secondary peak is produced mainly by photons at $\lambda<5 \mathrm{~nm}$ (see Fox et al. [1995] and Bougher et al. [2001] for discussions of the X-ray control of the secondary peak (or ledge) in the Martian dayside ionosphere).

\subsection{Model Results}

[12] As described in Figure 1, the MGS observations in March 1999 relate to rather unusual conditions (summer solstice, with early morning solar illumination at high latitude). These are dictated by the Earth-Mars-MGS occultation geometry and are not ideal conditions for modeling. Our approach therefore is to use the model for both the MGS observation point, as well as the latitude of the subsolar point $\left(24^{\circ} \mathrm{N}\right)$. This will provide a contrasting test case between a "regular" photochemical layer for which the solar zenith angle changes dramatically in the course of a day versus the MGS polar summer condition of minimal diurnal variation in solar illumination.

[13] Figure 3a shows the model's noontime electron density profile for average SOLAR 2000 irradiance conditions in March 1999 at the subsolar point on Mars $\left(24^{\circ} \mathrm{N}\right)$. The computed $\mathrm{Ne}_{\max }$ value would thus correspond to the highest electron density to be found on the planet at that time. Note the appearance of two layers, with the peak height at $\sim 120-130 \mathrm{~km}$ and a secondary ledge at $\sim 90 \mathrm{~km}$. In Figure $3 b$, the full diurnal cycle for peak density is shown. The typically symmetrical daily pattern associated with a photochemically dominated ionospheric layer is clearly evident. Figure $3 \mathrm{c}$ gives the results from a similar computation of the profile at latitude $71^{\circ} \mathrm{N}$ and 0400 local time, the average location of MGS observations in March 1999. The main and secondary peaks are found at higher altitudes, $138 \mathrm{~km}$ and $100 \mathrm{~km}$, respectively, due to the higher solar zenith angles. Figure $3 \mathrm{~d}$ gives the corresponding diurnal pattern for $\mathrm{Ne}_{\max }$ at that location. Note the presence of significant ionization during the nighttime hours, a consequence of the presence of the Sun above the horizon at this location. The mean of the MGS observations for both $\mathrm{Ne}(\mathrm{h})$ and $\mathrm{Ne}_{\max }$ taken from Figure 1 are also shown in Figures $3 \mathrm{c}$ and $3 \mathrm{~d}$, respectively. The comparison of absolute values is favorable (especially near the peak), providing confidence that the limited number of species and reactions in the model, plus the chosen neutral atmosphere, are acceptable for variability studies.

[14] There are also some simple checks possible to see if the numerical results in Figure 3 are in agreement with basic Chapman theory. For example, the ratio of electron density values at $71^{\circ}$ latitude for midnight and noon conditions should depend only on the ratio of $(\cos \chi)^{1 / 2}$ at each time, where $\chi$ is solar zenith angle. From Figure $3 b$, the average noontime value (with $\chi=47.7^{\circ}$ ) is $1.67 \times 10^{5} \mathrm{el} / \mathrm{cm}^{3}$, and the midnight value $\left(\chi=85.7^{\circ}\right)$ is $5.41 \times 10^{4} \mathrm{el} / \mathrm{cm}^{3}$. Their ratio is $\sim 3$. while the ratio of the square roots of their cos $\chi$ values is $\sim 3.0$. This provides additional confidence in the model's representation of basic photochemical processes.

[15] The results in Figure 3 are also in overall agreement with past modeling studies for MGS observations. In Figure $3 c$, the magnitude of the secondary ledge is noticeably smaller than the observations. The source of this difference could be the uncertain way we are handling the secondary ionization parameter or the value of the XUV irradiance. Additional X-ray ionizing radiation may help to increase the value of the secondary ledge [Bougher et al., 2001].

[16] Confident that the model reproduces mean behavior, we now present in Figure 4, the solar photon flux in 39 bins of wavelength from the SOLAR-2000 model output for each of the 17 days shown in Figure 1. The variability is quite evident in practically all the bins in the EUV and XUV spectrum. During this month, an active region on the Sun resulted in an F10.7 radio flux (the traditional indicator of solar activity) of $\sim 120$ units on the 9 th, reaching a maximum of $\sim 153$ from the 15 th -18 th, and then decaying to $\sim 105$ on the 27 th. These are not modest changes in solar flux, and are more typical of portions of a full solar cycle. In Figure 5a, we present the results of using the 17 daily solar spectra from Figure 4 in model calculations for $71^{\circ} \mathrm{N}$ and 0400 local time. The observed variability in electron density at the peak was $\sim 5 \%$ and $\sim 10 \%$ at the secondary peak (both computed from the mean of the observed profiles in Figure 1c). The variability from the model (Figure 5b) is $\sim 6 \%$ at the peak and $\sim 19 \%$ at the secondary peak (computed from the model's mean curve in Figure 3c). The calculated main peak variability matches the observed variability rather well; for the secondary ledge, however, the variability from the model is larger than observed. There are several possible sources for this: (1) the simple param- 


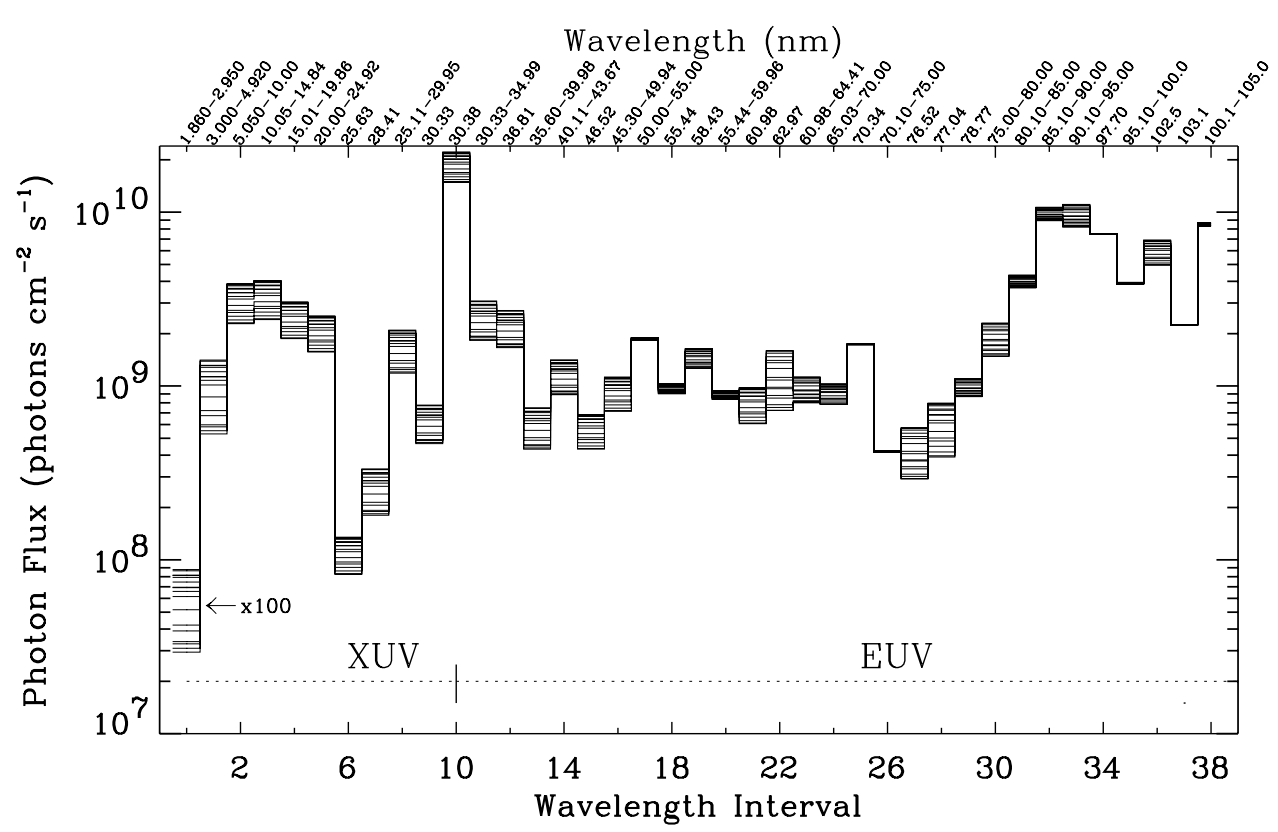

Figure 4. Solar photon flux versus wavelength from SOLAR2000 model for the 9-27 March 1999 period. The XUV spectral range includes wavelengths from 1.8 to $30 \mathrm{~nm}$. The EUV range goes from 30 to $100 \mathrm{~nm}$. The first wavelength bin has been multiplied by 100 for display purposes.

eterization of secondary ionization, (2) the high variability in the small wavelength bins in SOLAR2000 (X-ray emission below $5.0 \mathrm{~nm}$ is not well modeled by the F10.7 coronal proxy used in SOLAR2000 v1.24), and (3) the use of a constant neutral atmosphere. We notice that in the model the secondary peak is a well-defined feature and always present in the electron density profiles, while the observations show it more as a ledge or shoulder that sometimes is not even present. Clearly, more work is needed for a more complete understanding of "bottomside" electron densities on Mars.

[17] A reverse situation occurs between observations and model results when layer heights are examined. The altitudes of the main and secondary peaks do not change in the model, while there are evident variations in the observed profiles. This is readily understood as due to the fixed neutral atmosphere used in the model. Any vertical motions
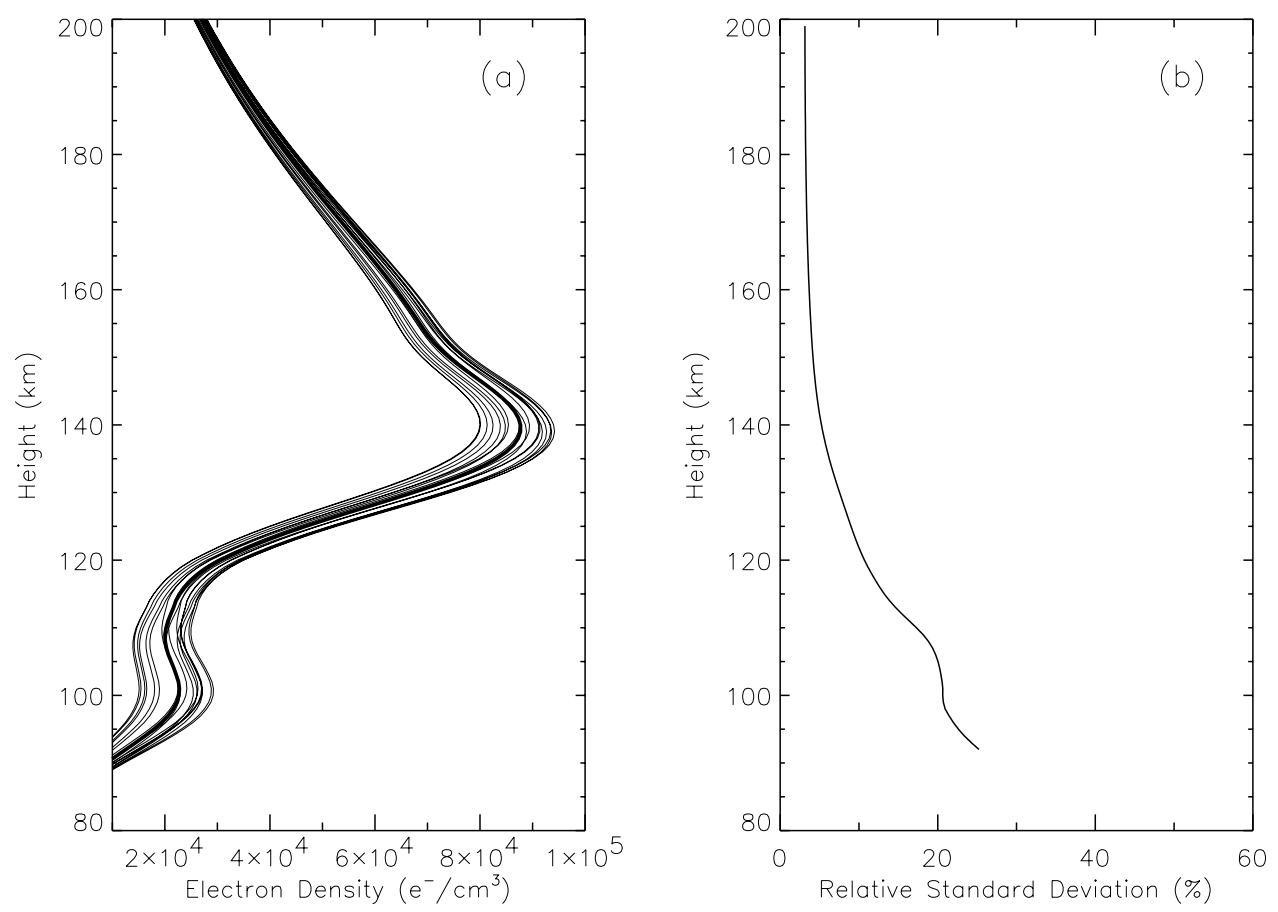

Figure 5. (a) Calculated electron density profiles for the period 9-27 March 1999 and (b) their variability. Compare with Figures $1 \mathrm{a}$ and $1 \mathrm{~b}$; see text. 
of the atmosphere would results in vertical displacements of the heights of the peaks, as shown clearly by Bougher et al. [2001]. Photochemical processes are independent of actual heights, i.e., an ionospheric peak forms at a constant optical depth $(\tau)$ not at a constant height, and thus ionospheric peaks occur at constant column-content levels [Mendillo et al., 2003].

[18] Finally, we note that the topside electron densities in Figure 5a are larger in the model than in the MGS observations in Figure 1. Topside variabilities (Figure 5b) are smaller than observed (Figure 1b). Again, these are due to the inappropriate use of a purely photochemical model at altitudes where plasma diffusion can be significant, as pointed out also by Bougher et al. [2001] in their photochemical modeling of MGS data. Other processes not considered in our model, and ones that could affect absolute electron densities above the peak and their day-to-day variabilities, are (1) uncertainties in the He $30.4 \mathrm{~nm}$ fluxes that dominate topside production (see Figure 2), (2) topside effects related to solar wind interactions with the ionosphere, and (3) the influence of crustal magnetic fields (as recently described by Ma et al. [2002]). For future studies of day-to-day variability in the upper ionosphere and especially in the Southern Hemisphere these processes certainly need to be included.

\section{Summary and Conclusions}

[19] Results from a basic photochemical model reproduce in a satisfactory way the observed peak electron densities from the MGS RS experiment for the period 9-27 March 1999. A main peak of $\sim 8.5 \times 10^{4} \mathrm{el} / \mathrm{cm}^{3}$ was produced at $\sim 140 \mathrm{~km}$ and a secondary ledge of $\sim 2 \times 10^{4} \mathrm{el} / \mathrm{cm}^{3}$ at $\sim 105 \mathrm{~km}$, both at $\sim 0400 \mathrm{LT}$ and a latitude of $\sim 71^{\circ}$ degrees. Moreover, using daily spectra from a solar irradiance model, the observed day-to-day variability in the MGS observations was also reproduced. While our main concern was to explain the behavior of the main peak density and its variability, issues remain for the low-altitude peak that the model reproduced less satisfactorily. With the inclusion of new X-ray data from the SNOE and TIMED satellites for the lower wavelength bins in SOLAR2000, an improved agreement should be obtained. The model also used a constant neutral atmosphere, and thus changes in the peak heights of the layers due to atmospheric motions could not be addressed. Nevertheless, the results show that photochemical processes, long known to dominate the average structure of Mars' ionosphere [Hantsch and Bauer, 1990], are also the framework for understanding day-to-day variability.

[20] Acknowledgments. This work was supported, in part, by the NASA's MGS Data Analysis grants program, by the NSF aeronomy program, and by seed research funds from the Center for Space Physics at Boston University.
[21] Arthur Richmond thanks Stephen W. Bougher and W. Kent Tobiska for their assistance in evaluating this paper.

\section{References}

Banks, P., and G. Kockarts, Aeronomy, Academic, San Diego, Calif., 1973. Bougher, S. W., and R. G. Roble, Comparative terrestrial planet thermospheres: 1. Solar cycle variation of global mean temperatures, J. Geophys. Res., 96, 11,045-11,055, 1991.

Bougher, S. W., S. Engel, R. G. Roble, and B. Foster, Comparative terrestrial planet thermospheres: 2 . Solar cycle variation of global structure and winds at equinox, J. Geophys. Res, 104, 16,591-16,611, 1999.

Bougher, S. W., S. Engel, R. G. Roble, and B. Foster, Comparative terrestrial planet thermospheres: 3 . Solar cycle variation of global structure and winds at solstices, J. Geophys. Res, 105, 17,669-17,692, 2000.

Bougher, S., S. Engel, D. Hinson, and J. Forbes, Mars Global Surveyor radio science electron density profiles: Neutral atmosphere implications, Geophys. Res. Lett., 28, 3091-3094, 2001.

Bougher, S. W., R. G. Roble, and T. Fuller-Rowell, Simulations of the upper atmospheres of the terrestrial planets, in Atmospheres in the Solar System: Comparative Aeronomy, Geophys. Monogr. Ser., vol. 130, edited by M. Mendillo, A. Nagy, and J. H. Waite, AGU, Washington, D. C., 2002.

Crider, D., et al., Magnetic field draping around Mars: Mars global surveyor results, Adv. Space Res., 27(11), 1831-1836, 2001.

Fox, J. L., Upper limits to the outflow of ions at Mars: Implications for atmospheric evolution, Geophys. Res. Lett, 24, 2901-2904, 1997.

Fox, J. L., P. Zhou, and S. W. Bougher, The Martian thermosphere/ionosphere at high and low solar activities, Adv. Space Res., 17(11), 203-218, 1995.

Keating, G. M., and S. W. Bougher, Isolation of major Venus thermospheric cooling mechanism and implications for Earth and Mars, J. Geophys. Res., 97, 4189-4197, 1992.

Hantsch, M. H., and S. J. Bauer, Solar control of the Mars ionosphere, Planet. Space Sci., 38, 539-542, 1990.

Ma, Y., A. F. Nagy, K. C. Hansen, D. L. DeZeeuw, T. I. Gombosi, and K. G. Powell, Three dimensional multispecies MHD studies of the solar wind interaction with Mars in the presence of crustal fields, J. Geophys. Res., 107(A10), 1282, doi:10.1029/2002JA009293, 2002.

Mendillo, M. J., S. M. Smith, J. L. Wroten, H. Rishbeth, and D. P. Hinson, Simultaneous ionospheric variability on Earth and Mars, J. Geophys. Res., 108, doi:10.1029/2003JA009961, in press, 2003.

Nagy, A., and T. Cravens, Solar system ionospheres, in Atmospheres in the Solar System: Comparative Aeronomy, Geophys. Monogr. Ser., vol. 130, edited by M. Mendillo, A. Nagy, and J. H. Waite, AGU, Washington, D. C., 2002.

Rishbeth, H., and O. K. Garriott, Introduction to Ionospheric Physics, Academic, San Diego, Calif., 1969.

Schunk, R., and A. Nagy, Ionospheres: Physics, Plasma Physics, and Chemistry, Cambridge Univ. Press, New York, 2000.

Tobiska, W. K., SOLAR2000 irradiances for climate change, aeronomy, and space system engineering, Adv. Space Res., in press, 2003.

Tobiska, W. K., et al., The SOLAR2000 empirical solar irradiance model and forecast tool, J. Atm. Solar Terr. Phys., 62, 1233-1250, 2000.

Verner, D. A., G. J. Ferland, K. T. Korista, and D. G. Yakovlev, Atomic data for astrophysics. II. New analytic fits for photoionization cross sections of atoms and ions, Astrophys. J., 465, 487, 1996.

Vignes, D., et al., The solar wind interaction with Mars: Locations and shapes of the bow shock and the magnetic pile-up boundary from the observations of the MAG/ER experiment onboard Mars Global Surveyor, Geophys. Res. Lett., 27, 49-52, 2000.

Vignes, D., M. H. Acuña, J. E. P. Connerney, D. H. Crider, H. Rème, and C. Mazelle, Factors controlling the location of the Bow Shock at Mars, Geophys. Res. Lett., 29(9), 1328, doi:10.1029/2001GL014513, 2002.

Winchester, C., and D. Rees, Numerical models of the Martian coupled thermosphere and ionosphere, Adv. Space Res., 15(4), 51-68, 1995.

C. R. Martinis, M. J. Mendillo, and J. K. Wilson, Center for Space Physics, Boston University, 725 Commonwealth Avenue, Boston, MA 02215, USA. (martinis@bu-ast.bu.edu; mendillo@bu.edu; jkwilson@bu. edu) 